\title{
Practice-Based Research Collaborative in Evidence-Based Dentistry
}

National Cancer Institute

\section{Source}

National Cancer Institute. Practice-Based Research Collaborative in Evidence-Based

Dentistry. NCl Thesaurus. Code C62551.

A network of dental practices that will establish the infrastructure to perform a wide variety of oral health research studies in Idaho, Montana, Oreg on, Utah and Washington. 